\title{
Left ventricular ejection hemodynamics before and after relief of outflow tract obstruction in patients with hypertrophic obstructive cardiomyopathy and valvular aortic stenosis
}

Hao Cui, MD, PhD, ${ }^{a}$ Hartzell V. Schaff, MD, ${ }^{a}$ Martin D. Abel, MD, ${ }^{b}$ Meghana R. K. Helder, MD, ${ }^{a}$ Robert L. Frye, MD, ${ }^{c}$ Steve R. Ommen, $M D,{ }^{c}$ and Rick A. Nishimura, MD

\section{ABSTRACT}

Objective: There has been debate on the importance and pathophysiologic effects of the dynamic subaortic pressure gradient in hypertrophic obstructive cardiomyopathy. The study was conducted to elucidate the hemodynamic abnormalities associated with the dynamic pressure gradient in hypertrophic obstructive cardiomyopathy.

Methods: Eight patients with hypertrophic obstructive cardiomyopathy and 7 patients with valvular aortic stenosis underwent a detailed hemodynamic study of pressure flow relationships before and after myectomy or aortic valve replacement during operation.

Results: In aortic stenosis, the increased gradient after premature ventricular contraction was associated with an increase in peak flow $(325 \pm 122 \mathrm{~mL} / \mathrm{s}$ to $428 \pm 147 \mathrm{~mL} / \mathrm{s}, P=.002)$ and stroke volume $(75.0 \pm 27.3 \mathrm{~mL}$ to $88.0 \pm 24.0 \mathrm{~mL}, P=.004$ ), but in hypertrophic obstructive cardiomyopathy peak flow remained unchanged $(289 \pm 79 \mathrm{~mL} / \mathrm{s}$ to $299 \pm 85 \mathrm{~mL} / \mathrm{s}, P=.334)$ and stroke volume decreased $(45.9 \pm 18.7 \mathrm{~mL}$ to $38.4 \pm 14.4 \mathrm{~mL}, P=.04)$ on the postpremature ventricular contraction beat. After myectomy, the capacity to augment stroke volume on the postpremature ventricular contraction beats was restored in patients with hypertrophic obstructive cardiomyopathy $(45.6 \pm 14.4 \mathrm{~mL}$ to $54.4 \pm 11.8 \mathrm{~mL}, P=.002)$.

Conclusions: The pressure flow relationship in hypertrophic obstructive cardiomyopathy supports the concept of true obstruction to outflow, with a low but continued flow during late systole, when the ventricular-aortic pressure gradient

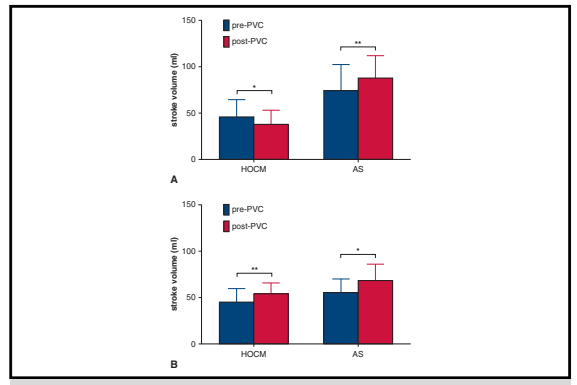

Changes in stroke volume before (A) and after (B) relief of obstruction in HOCM and AS.

\section{Central Message}

The LVOT obstruction in HOCM limits stroke volume, which may explain fatigue and poor exercise capacity. Abnormal ejection hemodynamics with augmentation of stroke volume are restored after myectomy.

\section{Perspective}

Future studies should focus on diastolic hemodynamics in patients with HOCM to fully understand the pathophysiologic processes in this disease and aid in the development of new therapies.
Septal myectomy is the treatment of choice for patients with severe symptomatic hypertrophic obstructive cardiomyopathy (HOCM). ${ }^{1,2}$ This therapy targets the dynamic left

\footnotetext{
From the Departments of ${ }^{\mathrm{a} C}$ ardiovascular Surgery and ${ }^{\mathrm{c}}$ Cardiovascular Diseases, and ${ }^{\mathrm{b}}$ Division of Cardiovascular and Thoracic Anesthesia, Mayo Clinic, Rochester, Minn.

This study was supported by the Paul and Ruby Tsai Family.

Institutional Review Board: 15-004606 on December 17, 2015.

Received for publication Jan 10, 2019; revisions received March 7, 2019; accepted for publication March 21, 2019; available ahead of print April 30, 2019.

Address for reprints: Hartzell V. Schaff, MD, 200 First St SW, Rochester, MN 55905 (E-mail: schaff@mayo.edu).

0022-5223/\$36.00

Copyright (c) 2019 by The American Association for Thoracic Surgery

https://doi.org/10.1016/j.jtcvs.2019.03.071
}

ventricular outflow tract (LVOT) gradient, which occurs as the result of systolic anterior motion (SAM) of the mitral valve abutting against a hypertrophied basal septum. After myectomy, there is resolution of the outflow gradient, and most patients experience a sustained relief of symptoms. ${ }^{3-5}$

Scanning this QR code will take you to the article title page to access supplementary information.

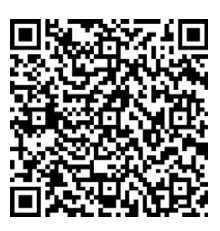




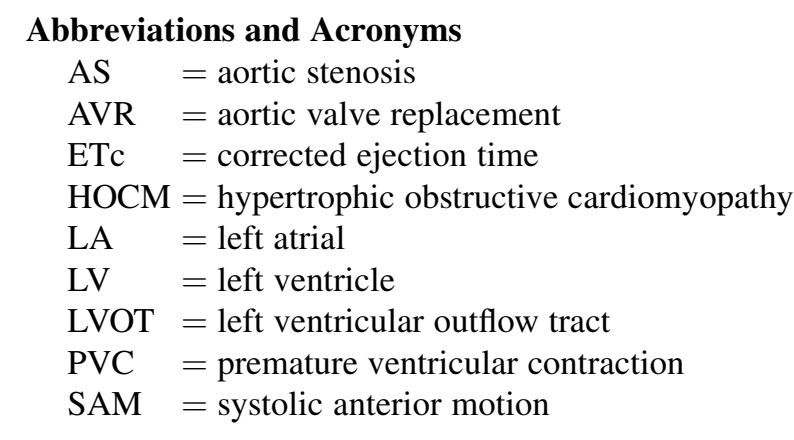

There has been controversy regarding the underlying pathophysiology of LVOT gradients in patients with HOCM. Some have questioned whether true obstruction does exist, based on the finding of early rapid emptying of the left ventricle (LV) in early systole with cessation of flow in mid and late systole. ${ }^{6-9}$ Others believe that true obstruction exists, but the exact mechanism by which this gradient affects cardiac function has not been well established. ${ }^{10-16}$ Although septal myectomy significantly decreases LVOT gradient and improves patients' functional capacity, it is not clear how the decreased gradient improves cardiac function. The present study was undertaken to elucidate the relationship between LVOT gradient and forward flow to understand the pathophysiology of HOCM.

\section{MATERIALS AND METHODS Study Population}

This study was approved by the Institutional Review Board of the Mayo Clinic. Eight patients with HOCM and 8 patients with aortic stenosis (AS) were enrolled and provided informed consent. The diagnosis of HOCM was made according to the American College of Cardiology/American Heart Association Guidelines on the Management of Patients with HOCM, and patients met the guideline criteria for operation. ${ }^{1}$ Transaortic septal myectomy was performed as previously described. ${ }^{17,18}$ Patients with AS in this study all had severe symptomatic AS and underwent conventional aortic valve replacement (AVR). One enrolled patient with AS was excluded from the study cohort because of low-quality aortic flow tracings.

\section{Hemodynamic Measurement}

Hemodynamic parameters including LV pressure, aortic pressure, left atrial (LA) pressure, and aortic flow were obtained before and after cardiopulmonary bypass. Before cardiopulmonary bypass, a calibrated, highfidelity, micromanometer-tipped catheter (Millar Instruments, Houston, Tex) was inserted in the ascending aorta at the site of the tack vent used for cardioplegia infusion and deairing. The catheter was positioned 2 to $3 \mathrm{~cm}$ above the aortic valve for measurements. An ultrasonic flow probe (Transonic Systems, Ithaca, NY) was placed around the ascending aorta to obtain simultaneous pressure and flow readings. A high-fidelity micromanometer-tipped catheter was inserted into the LV through the right ventricle or through the apex of the LV. A fluid-filled catheter was inserted into the left atrium to measure LA pressure. The micromanometer pressures were calibrated to pressures obtained from fluid-filled catheters as previously described. ${ }^{19}$ Rapid acquisition (5-ms intervals) digital values were continuously recorded before and after cardiopulmonary bypass. After measurement of hemodynamics in the baseline state, a premature ventricular contraction (PVC) was provoked, with repeat measurements made on the beat after the PVC after the induced pause. PVC was induced by mechanical stimulation of the right ventricle. After measurements, cannulas were placed for cardiopulmonary bypass, and after the procedures and decannulation, pressure catheters were reinserted at the same sites for postbypass hemodynamic measurements. The flow probes were again placed around the ascending aorta for simultaneous flow measurements. After hemodynamic stabilization, all measurements were obtained again during regular beats and on the beat after a provoked PVC. Hemodynamic data were acquired through a Mac-Lab recording system (GE Healthcare, Chicago, Ill) and stored online on a secure server.

\section{Data Analysis}

As illustrated in Figure 1, ejection time was defined as the period between aortic valve opening and aortic closure. The ejection time corrected for heart rate (corrected ejection time [ETc]) was obtained by dividing the measured ejection time by the square root of the heart cycle length. ${ }^{20}$ Several (at least 3) sequential beats were chosen for the baseline state. All pressure and flow measurements were made from the average of 3 or more beats. The aortic flow curves were analyzed from the start of ejection to the end of ejection. The area underneath the flow curve throughout all of ejection was used to calculate stroke volume. First half-time volume was defined as the volume proportion accumulated in the first half of flow time. All pressure and flow measurements were made during regular beats before and after cardiopulmonary bypass. The beat after a long pause following a provoked PVC was analyzed both before and after cardiopulmonary bypass.

The Kolmogorov-Smirnov test was used to assess the normality of the data before comparison. Normally distributed data were expressed as mean \pm standard deviation. Paired $t$ test was used for comparison of the same parameters from different times, and independent $t$ test was used for intergroup comparison. Skewed data were expressed as median (interquartile range). Wilcoxon signed-ranks test was used for paired data, and Mann-Whitney $U$ test was used for independent data. Categoric variables were compared with the chi-square test. Because of the 2 (pre-PVC vs postPVC) $\times 2$ (prebypass vs postbypass) $\times 2$ (HOCM vs AS) and multiple uncontrolled confoundings (changes in preload, afterload, and inotropy after bypass), the target comparisons were conducted between regular and postPVC beats. All statistics were performed with SPSS 22.0 package (IBM, Armonk, NY). Figures were plotted with Prism GraphPad 7.0 (GraphPad Software, Inc, San Diego, Calif).

\section{RESULTS \\ Patient Population}

All participants underwent successful surgical treatment with no mortality (Table 1). Mean ages at operation were $62.4 \pm 6.5$ years and $67.4 \pm 8.3$ years for the HOCM and AS groups, respectively $(P=.209)$. There was no difference in average height and weight between the 2 groups. Preoperative transthoracic echocardiography revealed greater septal thickness in those with HOCM compared with those with AS $(16.6 \pm 3.9 \mathrm{~mm}$ vs $12.4 \pm 2.3 \mathrm{~mm}$, $P=.03$ ). One patient in the HOCM group had latent LVOT obstruction with a baseline pressure gradient of $19 \mathrm{~mm} \mathrm{Hg}$, which increased to $71 \mathrm{~mm} \mathrm{Hg}$ after the Valsalva maneuver. All others had baseline resting pressure gradients greater than $50 \mathrm{~mm} \mathrm{Hg}$. Six of the patients with HOCM had moderate or severe secondary mitral valve regurgitation due 

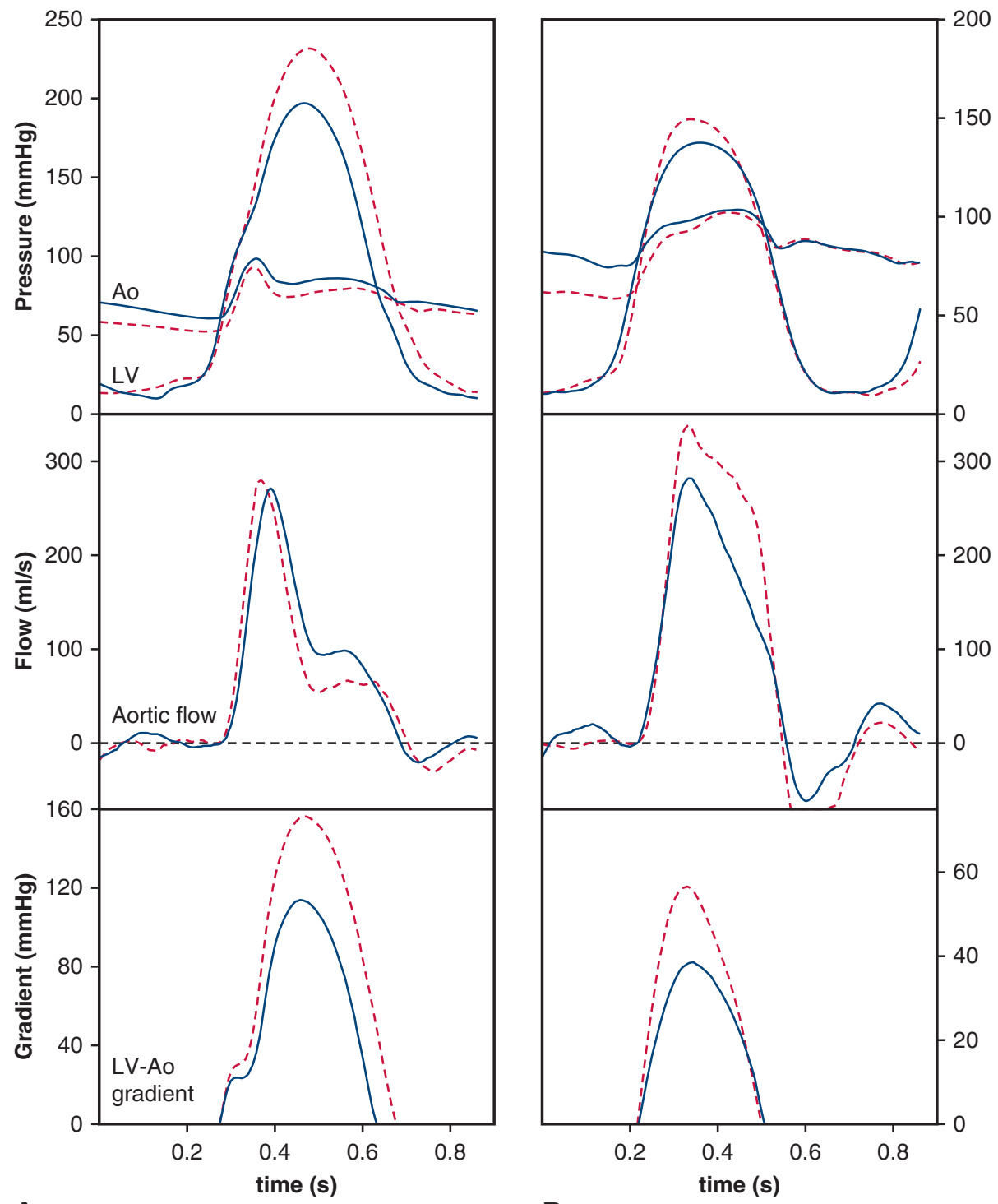

A

B

FIGURE 1. Pressure flow relationships in patients with HOCM and patients with AS. A, HOCM. B, Aortic valve stenosis. Blue solid line indicates a regular beat before PVC; red dashed line indicates the beat after PVC. There is a mid to late plateau in flow contour and an early plateau in pressure gradient in those with HOCM. In contrast, flow and pressure gradually increase and decrease in AS during ejection. Post-PVC beat in HOCM shows prolonged ejection (notch on aortic pressure tracing), unchanged peak flow (flow height), and decreased stroke volume (area under flow tracing). Post-PVC beat in AS shows unchanged ejection time, increased peak flow, and increased stroke volume. $L V$-Ao, Left ventricular aortic.

to the distortion of the mitral valve leaflets from the SAM, and 1 patient had moderate aortic valve regurgitation.

\section{Intraoperative Prebypass Hemodynamics}

After general anesthesia before cardiopulmonary bypass, 3 patients with HOCM had LVOT gradients of less than $30 \mathrm{~mm} \mathrm{Hg}$, but all patients had a gradient more than $100 \mathrm{~mm} \mathrm{Hg}$ after a PVC. None of the AS group had moderate mitral or aortic valve regurgitation. Patients in the HOCM and AS groups had a similar maximal LV dp/dt (HOCM $1077 \pm 186 \mathrm{~mm} \mathrm{Hg} / \mathrm{s}$ vs AS $1180 \pm 269 \mathrm{~mm}$
$\mathrm{Hg} / \mathrm{s}, P=.403)$. Changes in ejection hemodynamics on the post-PVC beat are shown in Table 2. In both groups, $\mathrm{LV}$ pressure, $\mathrm{LV}$-aortic pressure gradients, and $\mathrm{LV} \mathrm{dp} / \mathrm{dt}$ increased immediately after PVC. The LA pressure did not change on the post-PVC beats. In the HOCM group, there was a significant prolongation of the ETc on the post-PVC beat compared with the preceding beat. In the AS group, ETc did not change on the post-PVC beat. As shown in Figure 1, the patients with HOCM with a high gradient had a distinctive flow pattern of a rapid initial increase in flow in early systole, rapidly decreasing flow in 
TABLE 1. Demographic information and echocardiography data of patients

\begin{tabular}{lcccc}
\hline \multicolumn{1}{c}{ Variables } & HOCM $(\mathbf{n}=\mathbf{8})$ & AS $(\mathbf{n}=\mathbf{7})$ & \multicolumn{1}{c}{$\boldsymbol{P}$ value } \\
\hline Age $(\mathrm{y})$ & $65.0(61.3-66.0)$ & $66.0(61.0-73.0)$ & .397 \\
Male & $5 / 8$ & $173 \pm 11$ & .569 \\
Height $(\mathrm{cm})$ & $169 \pm 9$ & $77.3 \pm 20.8$ & .384 \\
Weight $(\mathrm{kg})$ & $83.3 \pm 24.3$ & $1.91 \pm 0.29$ & .624 \\
Body surface area $\left(\mathrm{m}^{2}\right)$ & $1.92 \pm 0.28$ & $25.4 \pm 4.6$ & .924 \\
Body mass index $\left(\mathrm{kg} / \mathrm{m}^{2}\right)$ & $29.2 \pm 8.3$ & $72.6 \pm 12.4$ & .300 \\
Pressure gradient $(\mathrm{mm} \mathrm{Hg})$ & $100.9 \pm 41.6 *$ & $60.4 \pm 10.1$ & .108 \\
LVEF $(\%)$ & $69.0 \pm 3.6$ & $12.4 \pm 2.3$ & .069 \\
Septal thickness $(\mathrm{mm})$ & $16.6 \pm 3.9 \dagger$ & $0 / 7$ & .028 \\
Moderate or severe mitral regurgitation & $6 / 8$ & $51(50.0-53.0)$ & .007 \\
\hline LV end-diastolic diameter $(\mathrm{mm})$ & $48.5(43.8-51.0)$ & .232 \\
\hline
\end{tabular}

Numbers in brackets indicate interquartile range. $H O C M$, Hypertrophic obstructive cardiomyopathy; $A S$, aortic stenosis; $L V E F$, left ventricular ejection fraction; $L V$, left ventricular. *Provoked gradient was used if gradient at rest was less than $30 \mathrm{~mm} \mathrm{Hg}$. †Basal thickness $20.3 \pm 2.3 \mathrm{~mm}$.

mid-systole, then plateauing and continuing at a lower velocity throughout the rest of the systolic ejection period. There was discordance in simultaneous analysis of the LV-aortic pressure gradient and aortic flow, with flow rapidly decreasing as the gradient increased. In contrast, all patients with AS had a similar flow curve (Figure 1).
There was a gradual increase in flow peaking in midsystole with a gradual decrease in flow until aortic valve closure. This normal flow contour was similar to the LVaortic pressure gradient throughout the systolic ejection period. In the patients with HOCM with minimal gradients, there was a similar flow contour to those with AS. However,

TABLE 2. Intraoperative hemodynamics of patients with hypertrophic obstructive cardiomyopathy and aortic stenosis before and after cardiopulmonary bypass

\begin{tabular}{|c|c|c|c|c|c|c|c|c|c|c|c|c|}
\hline \multirow[b]{3}{*}{ Variables } & \multicolumn{6}{|c|}{ Prebypass } & \multicolumn{6}{|c|}{ Postbypass } \\
\hline & \multicolumn{3}{|c|}{ HOCM } & \multicolumn{3}{|c|}{$\mathbf{A S}$} & \multicolumn{3}{|c|}{ HOCM } & \multicolumn{3}{|c|}{$\mathbf{A S}$} \\
\hline & Pre-PVC & Post-PVC & $P$ & Pre-PVC & Post-PVC & $P$ & Pre-PVC & Post-PVC & $P$ & Pre-PVC & Post-PVC & $P$ \\
\hline $\begin{array}{l}\text { Peak LVP } \\
(\mathrm{mm} \mathrm{Hg})\end{array}$ & $170.4 \pm 45.8$ & $218.1 \pm 44.6$ & $<.001$ & $147.8 \pm 21.7$ & $169.5 \pm 25.5$ & .029 & $139.6 \pm 12.2$ & $140.9 \pm 15.3$ & .612 & $119.8 \pm 17.5$ & $118.3 \pm 14.8$ & .634 \\
\hline $\begin{array}{l}\text { P-P gradient } \\
(\mathrm{mm} \mathrm{Hg})\end{array}$ & $75.0 \pm 50.9$ & $132.7 \pm 43.9$ & $<.001$ & $39.1 \pm 17.4$ & $59.5 \pm 20.5$ & .005 & $4.1 \pm 5.3$ & $8.8 \pm 10.2$ & .063 & $2.3 \pm 6.2$ & $3.7 \pm 7.0$ & .068 \\
\hline $\begin{array}{r}\text { MI gradient } \\
(\mathrm{mm} \mathrm{Hg})\end{array}$ & $78.6 \pm 52.5$ & $149.5 \pm 50.2$ & $<.001$ & $54.1 \pm 17.8$ & $79.9 \pm 20.8$ & .001 & $17.4 \pm 6.4$ & $25.0 \pm 8.3$ & $<.001$ & $16.9 \pm 10.9$ & $27.5 \pm 11.4$ & $<.001$ \\
\hline $\begin{array}{r}\text { Max LV dp/dt } \\
(\mathrm{mm} \mathrm{Hg} / \mathrm{s})\end{array}$ & $1077 \pm 186$ & $1411 \pm 291$ & .007 & $1180 \pm 269$ & $1709 \pm 470$ & .002 & $1194 \pm 133$ & $1508 \pm 142$ & .001 & $1312 \pm 472$ & $1631 \pm 573$ & .010 \\
\hline $\begin{array}{l}\text { Peak LAP } \\
\quad(\mathrm{mm} \mathrm{Hg})\end{array}$ & $39.1 \pm 28.8$ & $42.2 \pm 30.0$ & .231 & $23.9 \pm 9.7$ & $25.0 \pm 9.2$ & .226 & $19.1 \pm 7.8$ & $20.0 \pm 6.4$ & .315 & $18.0 \pm 6.1$ & $16.9 \pm 6.6$ & .040 \\
\hline $\begin{array}{l}\text { Mean LAP } \\
(\mathrm{mm} \mathrm{Hg})\end{array}$ & $23.3 \pm 13.5$ & $24.2 \pm 13.4$ & .330 & $14.4 \pm 4.9$ & $14.2 \pm 4.9$ & .645 & $14.1 \pm 4.0$ & $14.0 \pm 3.9$ & .864 & $12.1 \pm 4.3$ & $11.5 \pm 3.9$ & .154 \\
\hline $\begin{array}{l}\text { LAP V wave } \\
\text { (mm Hg) }\end{array}$ & $39.0 \pm 29.1$ & $39.1 \pm 24.6$ & .981 & $23.5 \pm 9.5$ & $24.9 \pm 9.4$ & .134 & $15.0 \pm 4.0$ & $15.5 \pm 4.8$ & .573 & $15.6 \pm 5.0$ & $16.1 \pm 5.0$ & .728 \\
\hline $\mathrm{ETc}(\mathrm{ms})$ & $427 \pm 58$ & $477 \pm 50$ & .006 & $393 \pm 18$ & $384 \pm 46$ & .548 & $330 \pm 50$ & $343 \pm 50$ & .058 & $326 \pm 23$ & $335 \pm 22$ & .382 \\
\hline $\begin{array}{r}\text { Peak flow } \\
(\mathrm{mL} / \mathrm{s})\end{array}$ & $289 \pm 79$ & $299 \pm 85$ & .334 & $325 \pm 122$ & $428 \pm 147$ & .002 & $293 \pm 75$ & $383 \pm 74$ & $<.001$ & $350 \pm 87$ & $450 \pm 117$ & .004 \\
\hline $\begin{array}{c}\text { Max flow df/dt } \\
\left(\mathrm{mL} / \mathrm{s}^{2}\right)\end{array}$ & $4990 \pm 994$ & $6004 \pm 1262$ & .028 & $4905 \pm 2608$ & $6488 \pm 3890$ & .038 & $4917 \pm 1141$ & $6071 \pm 1149$ & $<.001$ & $5380 \pm 1162$ & $8201 \pm 1594$ & .003 \\
\hline $\begin{array}{l}\text { Stroke volume } \\
\quad(\mathrm{mL})\end{array}$ & $45.9 \pm 18.7$ & $38.4 \pm 14.4$ & .043 & $75.0 \pm 27.3$ & $88.0 \pm 24.0$ & .004 & $45.6 \pm 14.4$ & $54.4 \pm 11.8$ & .002 & $55.4 \pm 15.1$ & $69.0 \pm 17.5$ & .041 \\
\hline $\begin{array}{l}\text { Stroke index } \\
\left(\mathrm{mL} / \mathrm{m}^{2}\right)\end{array}$ & $24.1 \pm 10.0$ & $20.2 \pm 8.3$ & .039 & $39.2 \pm 12.7$ & $46.1 \pm 10.6$ & .005 & $23.8 \pm 6.7$ & $28.4 \pm 5.2$ & .002 & $29.2 \pm 7.6$ & $36.4 \pm 8.8$ & .037 \\
\hline
\end{tabular}




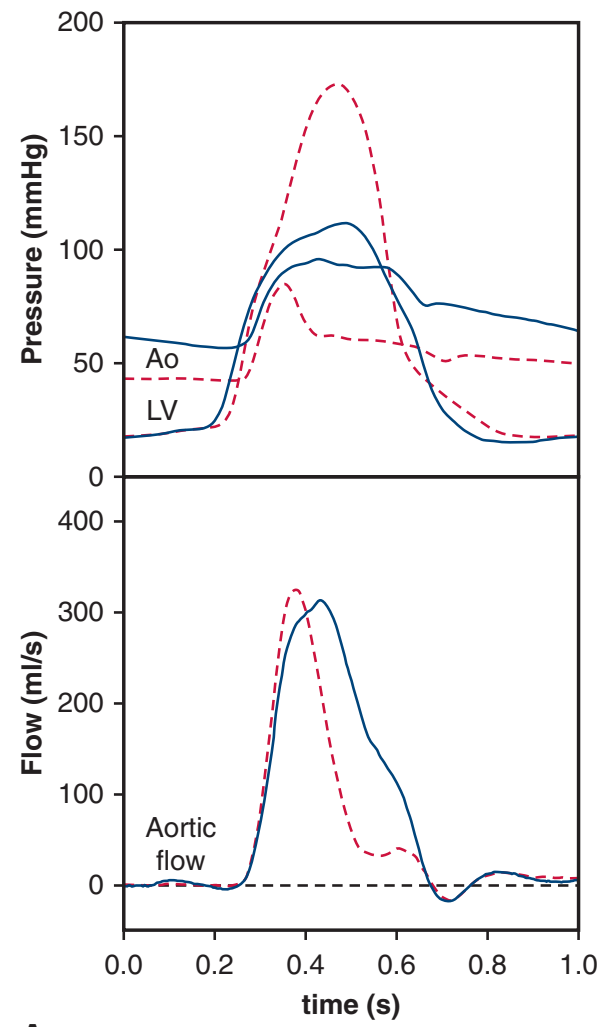

A

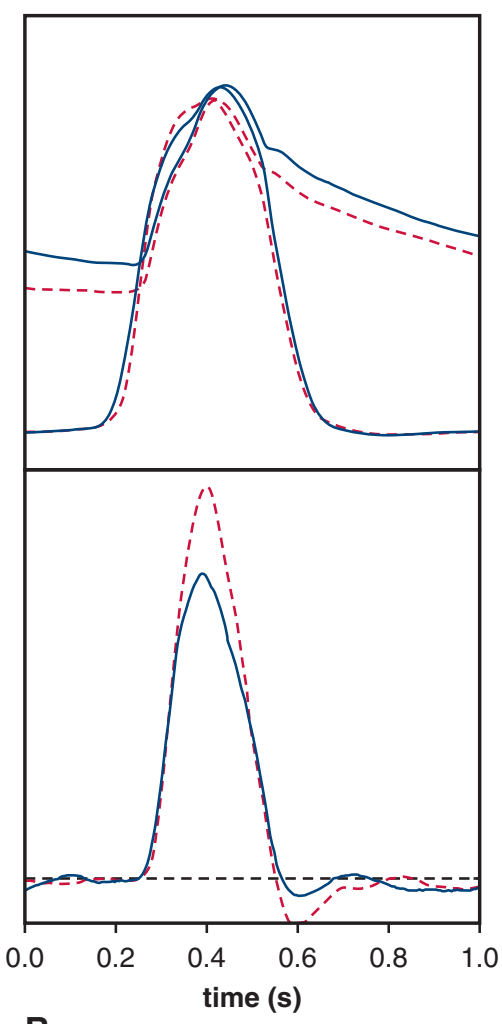

B

FIGURE 2. Pressure flow relationships in a patient with labile LVOT gradient before (A) and after myectomy (B). Blue solid line indicates a regular beat before PVC; red dashed line indicates the beat after PVC. Before myectomy (A), provocation decreased late flow without altering peak flow, thereby compromising the stroke volume; after myectomy, provocation simply increased the peak flow and resulted in an increase in stroke volume. Post-PVC beat before myectomy shows prolonged ejection (notch on aortic pressure tracing), unchanged peak flow (flow height), and decreased stroke volume (area under flow tracing). Post-PVC beat after myectomy (B) shows unchanged ejection time, increased peak flow, and increased stroke volume. $L V$, Left ventricular; Ao, aortic.

on the beat after a PVC, there was the distinctive flow pattern seen in patients with LVOT obstruction (Figure 2).

The stroke volume was calculated from the integrated area under the flow curve, and the results are shown in Figure $3, A$. In the HOCM group, the peak outflow remained unchanged after PVC (post-PVC $289 \pm 79 \mathrm{~mL} / \mathrm{s}$ vs prePVC $299 \pm 85 \mathrm{~mL} / \mathrm{s}, P=.334)$; however, the stroke volume was significantly lower after provocation (post-PVC $38.4 \pm 14.4 \mathrm{~mL}$ vs pre-PVC $45.9 \pm 18.7 \mathrm{~mL}, P=.043$ ). In patients with $\mathrm{AS}$, the stroke volume increased significantly on the post-PVC beat (post-PVC $88.0 \pm 24.0 \mathrm{~mL}$ vs pre-PVC $75.0 \pm 27.3 \mathrm{~mL}, P=.004)$.

\section{Intraoperative Postbypass Hemodynamics}

Six patients with HOCM underwent isolated septal myectomy. Two patients had myectomy and additional maze procedures, and 1 patient had septal myectomy and aortic valve repair. Only 1 patient had residual moderate mitral regurgitation after operation. All patients with AS underwent isolated AVR, including 5 patients with tissue AVR and 2 patients with mechanical AVR. As shown in
Table 3, both peak-peak gradients and maximal instantaneous gradients were greatly reduced. In patients with HOCM after myectomy, there was resolution of the dynamic LVOT gradient. In patients with AS, there was a resolution of the fixed aortic valve gradient after AVR. Postbypass heart rates were comparable to prebypass rates, but ETc was significantly shortened in both groups after relief of outflow tract obstruction.

The aortic flow curves were similar in both the HOCM and AS groups after myectomy or AVR. As shown in Figure 4, in the HOCM group after myectomy, the proportion of stroke volume in the first half of flow time decreased (prebypass $71.0 \% \pm 17.3 \%$ vs postbypass $53.8 \% \pm 6.2 \%, P=.030$ ), thereby demonstrating improved output capacity in the late phase of ejection. After AVR in the AS group, the first half-time stroke proportion was similar to the prebypass value (prebypass $57.2 \% \pm 4.2 \%$ vs postbypass $54.9 \% \pm 10.5 \%$, $P=.546$ ) (Figure 4). The maximum $\mathrm{LV} \mathrm{dp/dt} \mathrm{of} \mathrm{the}$ HOCM group was $1077 \pm 186 \mathrm{~mm} \mathrm{Hg} / \mathrm{s}$ prebypass and $1194 \pm 133 \mathrm{~mm} \mathrm{Hg} / \mathrm{s}$ postbypass $(P=.186)$. 


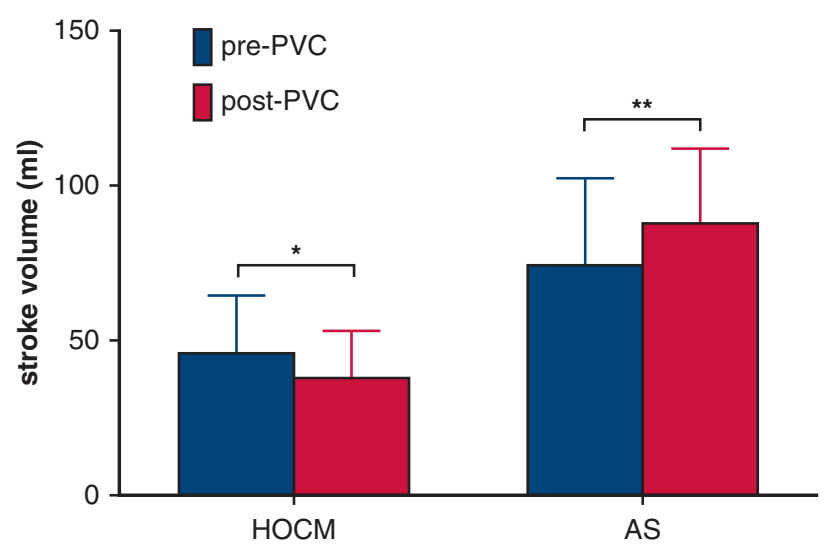

A

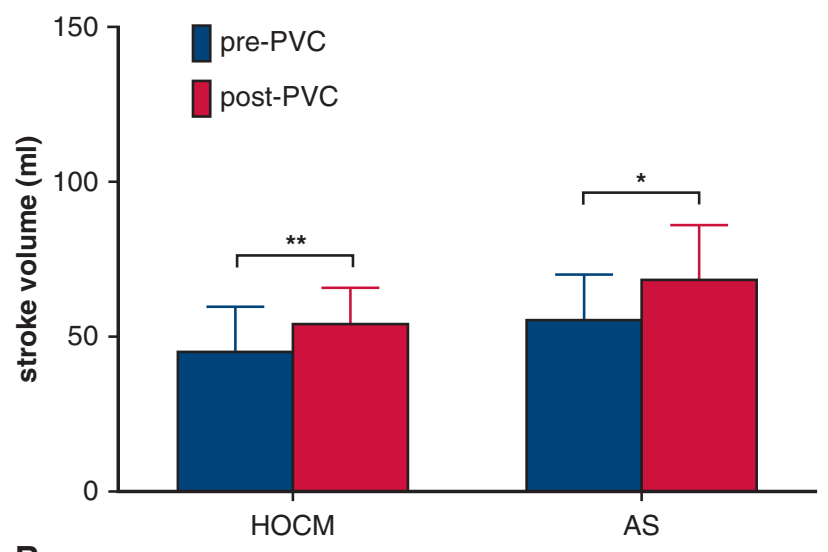

B

FIGURE 3. Changes in stroke volume comparing pre-PVC with postPVC beats before (A) and after (B) myectomy or AVR. A, Stroke volume of the HOCM group decreases after provocation in contrast to increasing post-PVC flow in the AS group. B, Myectomy in patients with HOCM restores the ability to augment stroke volume when challenged with a PVC. $P V C$, Premature ventricular contraction; HOCM, hypertrophic obstructive cardiomyopathy; $A S$, aortic stenosis. ${ }^{*} P<.05 . * * P<.01$.

Analysis of the post-PVC beats after bypass is shown in Table 2. In both groups, the maximal instantaneous gradient increased on the post-PVC beat compared with the pre-PVC beats, but remained less than $30 \mathrm{~mm} \mathrm{Hg}$. In the HOCM group, the ETc on the post-PVC beat was not different than the ETc on the preceding beat (post-PVC $343 \pm 50 \mathrm{~ms}$ vs pre-PVC $330 \pm 50 \mathrm{~ms}, P=.058)$ after myectomy.

After myectomy, patients with HOCM regained the capacity to augment the maximal flow (pre-PVC $293 \pm 75 \mathrm{~mL} / \mathrm{s}$ to post-PVC $383 \pm 74 \mathrm{~mL} / \mathrm{s}, P<.001)$ and stroke volume (pre-PVC $45.6 \pm 14.4 \mathrm{~mL}$ to postPVC $54.4 \pm 11.8 \mathrm{~mL}, P=.002$ ) after provocation. In the AS group, peak flow and stroke volume increased after provocation as occurred prebypass. After adjustment by pre-PVC stroke volume, the provoked proportional stroke volume increased from prebypass $-14.5 \% \pm 14.4 \%$ to
$23.2 \% \pm 18.6 \%(P=.002)$ after myectomy in the HOCM group. In contrast, in the AS group, provoked proportional stroke volume was $21.6 \% \pm 17.2 \%$ prebypass and $29.0 \% \pm 28.2 \%$ postbypass $(P=.555)$. The impact of myectomy and AVR on stroke volume is shown in Figure 3, B. Hemodynamic changes after PVC in patients with HOCM and AS are summarized in Table E1.

\section{DISCUSSION}

This study elucidates the hemodynamic abnormalities associated with the dynamic LVOT gradient in patients with hypertrophic cardiomyopathy. The results of this study support the concept of true obstruction to outflow, which is relieved by septal myectomy. As opposed to patients with fixed AS in whom obstruction begins at aortic valve opening and gradually increases and then decreases throughout the systolic ejection period, the obstruction in HOCM occurs in mid-to-late systole, compromising flow out of the LV. The relationship of the pressure gradient and aortic flow demonstrates that as the gradient increases in the mid and late stages of the systolic ejection period, the blood flow decreases but continues throughout all of systole.

Prior studies of flow in patients with HOCM have shown similar results, with a rapid decrease in flow during midsystole resulting in $70 \%$ to $80 \%$ of the stroke volume occurring in the first half of systole. ${ }^{10,21}$ In these studies, blood flow was measured by different methods. Pierce and associates ${ }^{10}$ used an electromagnetic flow probe around the ascending aorta, and Hernandez and colleagues ${ }^{21}$ calculated flow from pressure gradients. A catheter-based electromagnetic flow probe was used in the study by Murgo and colleagues. ${ }^{9}$ The concept that true obstruction does not exist emerged from the finding of cessation or minimal flow in mid-to-late systole ${ }^{9}$ coupled with angiographic evidence of rapid and complete emptying of the LV cavity. 8,22 However, the current investigation demonstrates that flow does continue throughout all of the systolic ejection period, supporting the concept of a true "obstruction" to flow. ${ }^{9,23-25}$ The initial high flow during early systole with significant reduction in flow during mid and late systole was a consistent finding in patients with hypertrophic cardiomyopathy who had a high gradient. This continued flow in mid-to-late systole was seen in earlier studies. ${ }^{10,11,21}$ The cessation of flow in other studies ${ }^{9}$ may be related to the methodology of using a flow probe on a single catheter placed in the ascending aorta where there may be abnormal flow profiles and vortices. This pattern was exaggerated on the beat after a PVC in patients who had resting obstruction. In those patients who had labile obstruction (no gradient before myectomy during regular beats but a gradient after a PVC), this pattern was not present before but was manifest after PVC. Also supporting the concept of obstruction were the changes in ETc, which increases with more severe obstruction. $^{20}$ In patients with HOCM, there was an 
TABLE 3. Intraoperative hemodynamics of patients with aortic stenosis and hypertrophic obstructive cardiomyopathy at regular beats before and after cardiopulmonary bypass

\begin{tabular}{|c|c|c|c|c|c|c|}
\hline \multirow[b]{2}{*}{ Variables } & \multicolumn{3}{|c|}{ HOCM } & \multicolumn{3}{|c|}{ AS } \\
\hline & Prebypass & Postbypass & $P$ & Prebypass & Postbypass & $P$ \\
\hline P-P gradient $(\mathrm{mm} \mathrm{Hg})$ & $75.0 \pm 50.9$ & $4.1 \pm 5.3$ & .005 & $39.1 \pm 17.4$ & $2.3 \pm 6.2$ & .002 \\
\hline Systolic aortic pressure (mm Hg) & $95.4 \pm 17.3$ & $135.5 \pm 13.2$ & $<.001$ & $108.6 \pm 19.3$ & $117.5 \pm 19.2$ & .084 \\
\hline Diastolic aortic pressure $(\mathrm{mm} \mathrm{Hg})$ & $55.3 \pm 11.2$ & $72.1 \pm 16.6$ & .033 & $61.5 \pm 14.0$ & $60.3 \pm 13.8$ & .757 \\
\hline MI gradient $(\mathrm{mm} \mathrm{Hg})$ & $78.6 \pm 52.5$ & $17.4 \pm 6.4$ & .011 & $54.1 \pm 17.8$ & $16.9 \pm 10.9$ & .002 \\
\hline Peak LVP (mm Hg) & $170.4 \pm 45.8$ & $139.6 \pm 12.2$ & .155 & $147.8 \pm 21.7$ & $119.8 \pm 17.5$ & .001 \\
\hline Peak LAP (mm Hg) & $27.9(23.9-55.9)$ & $15.5(12.8-27.0)$ & .050 & $28.6(11.3-28.9)$ & $16.7(14.9-21.2)$ & .063 \\
\hline Mean LAP (mm Hg) & $20.2(15.5-35.4)$ & $13.6(9.8-18.4)$ & .161 & $15.4(8.6-18.8)$ & $11.4(8.4-14.8)$ & .128 \\
\hline LAP V wave (mm Hg) & $39.0 \pm 29.1$ & $15.0 \pm 4.0$ & .067 & $23.5 \pm 9.5$ & $15.6 \pm 5.0$ & .036 \\
\hline Max LV dp/dt (mm Hg/s) & $1077 \pm 186$ & $1194 \pm 133$ & .186 & $1180 \pm 269$ & $1312 \pm 472$ & .368 \\
\hline Max flow df $/ \mathrm{dt}\left(\mathrm{mL} / \mathrm{s}^{2}\right)$ & $4990 \pm 994$ & $4917 \pm 1141$ & .898 & $4905 \pm 2608$ & $5380 \pm 1162$ & .671 \\
\hline ETc (ms) & $427 \pm 58$ & $330 \pm 50$ & $<.001$ & $393 \pm 18$ & $326 \pm 23$ & $<.001$ \\
\hline Peak flow $(\mathrm{mL} / \mathrm{s})$ & $289 \pm 79$ & $293 \pm 75$ & .945 & $325 \pm 122$ & $350 \pm 87$ & .649 \\
\hline Stroke volume (mL) & $45.9 \pm 18.7$ & $45.6 \pm 14.4$ & .977 & $75.0 \pm 27.3$ & $55.4 \pm 15.1$ & .019 \\
\hline FHT stroke $(\%)$ & $71.0 \pm 17.3$ & $53.8 \pm 6.2$ & .030 & $57.2 \pm 4.2$ & $54.9 \pm 10.5$ & .546 \\
\hline Heart rate (/min) & $62 \pm 19$ & $70 \pm 11$ & .241 & $67 \pm 13$ & $72 \pm 16$ & .399 \\
\hline Stroke index $\left(\mathrm{mL} / \mathrm{m}^{2}\right)$ & $24.1 \pm 10.0$ & $23.8 \pm 6.7$ & .946 & $39.2 \pm 12.7$ & $29.2 \pm 7.6$ & .023 \\
\hline Cardiac index $\left(\mathrm{L} / \mathrm{min} / \mathrm{m}^{2}\right)$ & $1.35 \pm 0.30$ & $1.64 \pm 0.43$ & .067 & $2.52 \pm 0.60$ & $2.06 \pm 0.61$ & .101 \\
\hline
\end{tabular}

Numbers in brackets indicate interquartile range. $H O C M$, Hypertrophic obstructive cardiomyopathy; $A S$, aortic stenosis; $P$ - $P$, peak to peak; $M I$, maximal instantaneous; $L V P$, left ventricular pressure; $L A P$, left atrial pressure; $E T c$, corrected ejection time; $F H T$, first half time.

increase in ETc on the beat after the PVC concomitant with the increase in LVOT gradient.

The novel finding in this study was the change in flow patterns after myectomy in patients with HOCM and valve replacement in patients with AS. After myectomy with resolution of the LVOT gradient, there was no longer an increase in the ETc on the beat after the PVC. The aortic flow pattern returned to normal both after AVR for AS and myectomy for HOCM. This demonstrates a similar cardiac hemodynamic response to the relief of afterload for both groups of patients, indicating that it was a dynamic obstruction and not early rapid filling that resulted in the unique flow pattern observed only in the presence of a high LVOT gradient. The lack of decrease in the peak positive $\mathrm{dp} / \mathrm{dt}$ in patients with HOCM after myectomy also supports the concept that there is true obstruction because relief of obstruction was not associated with a decrease in contractility; thus, change in contractility does not account for the flow changes.

An important finding in this study emerged from the ability to measure beat-to-beat stroke volume from the aortic flow curve. In patients with hypertrophic cardiomyopathy, the stroke volume significantly decreased on the beat after the PVC, in contrast to an increase in stroke volume on the post-PVC beat in patients with fixed AS. This was documented in 1964 by Pierce and colleagues. ${ }^{10}$ After myectomy, there was an increase in the post-PVC stroke volume in the patients with hypertrophic cardiomyopathy.
The decrease in stroke volume caused by the increase in obstruction most likely plays a major role in producing the signs and symptoms of patients with hypertrophic cardiomyopathy and may account for the significant relief of these symptoms after septal reduction therapy.

The changes in stroke volume after myectomy may be affected by SAM-mediated mitral regurgitation. On the basis of the data of the present study, however, we believe LVOT obstruction plays the dominant role in compromised forward flow. If reduced forward flow is primarily caused by increased regurgitation and resultant faster emptying of LV, LV ejection time would be reduced. In this study, however, ejection time was prolonged as obstruction increased, and it was significantly reduced after relief of obstruction. This meant that emptying of LV was delayed during systole because of obstruction. The obstructed forward flow was also demonstrated by restricted peak forward flow under higher LV pressure after provocation. Moreover, changes in mean LA pressure and peak LA pressure were minimal after provocation, whereas decrease of stroke volume was significant. Mitral regurgitation may provide an extra exit for the obstructed blood in the LV and thus may contribute to the reduced stroke volume, but it is not the primary cause of reduced forward flow.

This study clearly elucidates the obstructive physiology of HOCM. The often observed decrease in resting obstruction during general anesthesia simulates the negative chronotropic and inotropic effects of medical 


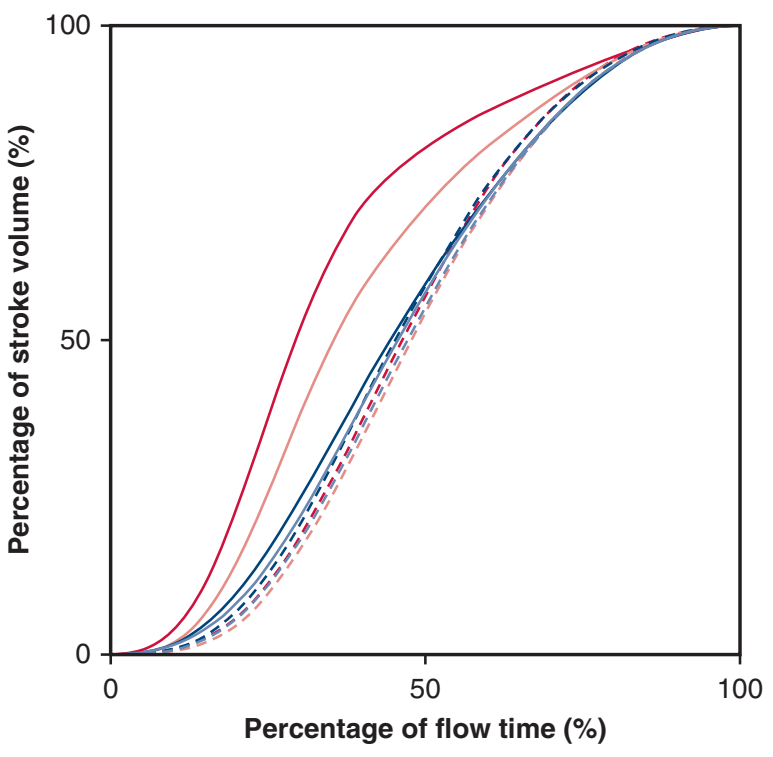

- HOCM prebypass pre-PVC - AS prebypass pre-PVC

- HOCM prebypass post-PVC - AS prebypass post-PVC

- - HOCM postbypass pre-PVC - - AS postbypass pre-PVC

- - HOCM postbypass post-PVC -- AS postbypass post-PVC

FIGURE 4. Cumulative proportion of stroke volume over the systolic ejection period. Septal myectomy shifts the volume-time curve of HOCM rightward by elevating the flow volume of the late ejection phase. HOCM, Hypertrophic obstructive cardiomyopathy; $P V C$, premature ventricular contraction; $A S$, aortic stenosis.

treatment. However, even under these conditions, there is substantially increased pressure gradient, prolonged ejection, and decreased stroke volume after provocation. Further, the unique ejection pattern may contribute to the pathophysiology of HOCM. This study documented a prolonged ejection time in patients with HOCM, especially after provocation, and the prolonged ejection time corresponds to longer QT interval, ${ }^{26}$ accentuates the ischemia, and predisposes to ventricular arrhythmias. This may explain the relatively high incidence of sudden cardiac death during exercise even in asymptomatic patients and the reduction in serious ventricular arrhythmias after myectomy. ${ }^{4}$ Thus, medical treatment may be effective in controlling symptoms at rest, but drug therapy does not correct the abnormal physiology of HOCM. This is further supported by studies of patients with HOCM and syncope who report less recurrent syncope and have superior survival after septal myectomy compared with medical treatment alone. ${ }^{27}$ Hypertrophic cardiomyopathy with LVOT obstruction is a structural heart disease that, in most patients, is best managed by anatomical intervention.

\section{Study Limitations}

Patients in the study had hemodynamic evaluation under general anesthesia, which may produce different loading conditions than while awake. The postsurgical measurements were made after cardiopulmonary bypass, which also causes some deviation from the normal physiologic status. Patients with hypertrophic cardiomyopathy frequently have mitral regurgitation secondary to distortion of the mitral valve apparatus during systole, and this additional pathophysiologic mechanism was not taken into account. The loading conditions intraoperatively under anesthesia might affect the LVOT gradient and consequently influence the hemodynamic measurements. Although other confounding factors, including heart rate, mitral regurgitations, and heart contractility, were well controlled in pre-PVC versus post-PVC comparisons, they might introduce some unknown influence on the results.

\section{CONCLUSIONS}

Obstruction in HOCM indeed exists. The flow-pressure relationships in patients with a dynamic LVOT gradient reflect impedance of forward blood flow in the middle and late phases of ejection. In contrast to findings with fixed $\mathrm{AS}$, there is a decrease in stroke volume as the LVOT gradient increases in patients with HOCM. Abolishing obstruction by septal myectomy restores the ability to augment stroke volume when challenged, a finding that explains improvement in exercise capacity postoperatively.

\section{Conflict of Interest Statement}

Authors have nothing to disclose with regard to commercial support.

\section{References}

1. Gersh BJ, Maron BJ, Bonow RO, Dearani JA, Fifer MA, Link MS, et al. 2011 ACCF/AHA guideline for the diagnosis and treatment of hypertrophic cardiomyopathy: a report of the American College of Cardiology Foundation/American Heart Association task force on practice guidelines. Developed in collaboration with the American Association for Thoracic Surgery, American Society of Echocardiography, American Society of Nuclear Cardiology, Heart Failure Society of America, Heart Rhythm Society, Society for Cardiovascular Angiography and Interventions, and Society of Thoracic Surgeons. J Am Coll Cardiol. 2011;58: e212-60.

2. Authors/Task Force, members, Elliott PM, Anastasakis A, Borggrefe M, Cecchi F, Charron P, et al. 2014 ESC guidelines on diagnosis and managemen of hypertrophic cardiomyopathy: the task force for the diagnosis and management of hypertrophic cardiomyopathy of the European Society of Cardiology (ESC). Eur Heart J. 2014;35:2733-79.

3. Ommen SR, Maron BJ, Olivotto I, Maron MS, Cecchi F, Betocchi S, et al. Longterm effects of surgical septal myectomy on survival in patients with obstructive hypertrophic cardiomyopathy. J Am Coll Cardiol. 2005;46:470-6.

4. McLeod CJ, Ommen SR, Ackerman MJ, Weivoda PL, Shen WK, Dearani JA, et al. Surgical septal myectomy decreases the risk for appropriate implantable cardioverter defibrillator discharge in obstructive hypertrophic cardiomyopathy. Eur Heart J. 2007;28:2583-8.

5. Geske JB, Konecny T, Ommen SR, Nishimura RA, Sorajja P, Schaff HV, et al Surgical myectomy improves pulmonary hypertension in obstructive hypertrophic cardiomyopathy. Eur Heart J. 2013;35:2032-9.

6. Criley JM. Unobstructed thinking (and terminology) is called for in the understanding and management of hypertrophic cardiomyopathy. J Am Coll Cardiol. 1997;29:741-3.

7. Murgo JP. Have we really come to understand the relationship between the left ventricular outflow tract gradient and left ventricular emptying in 
hypertrophic cardiomyopathy? J Am Coll Cardiol. 2010;55:608. author reply 608-9.

8. Criley JM, Lewis KB, White RI Jr, Ross RS. Pressure gradients without obstruction. A new concept of "hypertrophic subaortic stenosis". Circulation. 1965;32: $881-7$

9. Murgo JP, Alter BR, Dorethy JF, Altobelli SA, McGranahan GM Jr. Dynamics of left ventricular ejection in obstructive and nonobstructive hypertrophic cardiomyopathy. J Clin Invest. 1980;66:1369-82.

10. Pierce GE, Morrow AG, Braunwald E. Idiopathic hypertrophic subaortic stenosis. 3. Intraoperative studies of the mechanism of obstruction and its hemodynamic consequences. Circulation. 1964;30(Suppl 4):152-213.

11. Ross J Jr, Braunwald E, Gault JH, Mason DT, Morrow AG. The mechanism of the intraventricular pressure gradient in idiopathic hypertrophic subaortic stenosis. Circulation. 1966;34:558-78.

12. Maron BJ, Maron MS, Wigle ED, Braunwald E. Reply. J Am Coll Cardiol. 2010; 55:608-9.

13. Maron MS, Olivotto I, Zenovich AG, Link MS, Pandian NG, Kuvin JT, et al. Hypertrophic cardiomyopathy is predominantly a disease of left ventricular outflow tract obstruction. Circulation. 2006;114:2232-9.

14. Braunwald E. Obstruction in hypertrophic cardiomyopathy: how often does it occur? Should it be treated? If so, how? Circulation. 2012;126:2369-70.

15. Braunwald E, Lambrew CT, Rockoff SD, Ross J Jr, Morrow AG. Idiopathic hypertrophic subaortic stenosis. I. A description of the disease based upon an analysis of 64 patients. Circulation. 1964;30(Suppl 4):3-119.

16. Braunwald E, Brockenbrough EC, Frye RL. Studies on digitalis. V. Comparison of the effects of ouabain on left ventricular dynamics in valvular aortic stenosis and hypertrophic subaortic stenosis. Circulation. 1962;26:166-73.

17. Nishimura RA, Schaff HV. Evolving treatment for patients with hypertrophic obstructive cardiomyopathy. J Am Coll Cardiol. 2015;66:1697-9.

18. Nishimura RA, Seggewiss H, Schaff HV. Hypertrophic obstructive cardiomyopathy: surgical myectomy and septal ablation. Circ Res. 2017;121:771-83.
19. Ashikhmina EA, Schaff HV, Ommen SR, Dearani JA, Nishimura RA, Abel MD Intraoperative direct measurement of left ventricular outflow tract gradients to guide surgical myectomy for hypertrophic cardiomyopathy. J Thorac Cardiovasc Surg. 2011;142:53-9.

20. Wigle ED, Auger P, Marquis Y. Muscular subaortic stenosis. The direct relation between the intraventricular pressure difference and the left ventricular ejection time. Circulation. 1967;36:36-44.

21. Hernandez RR, Greenfield JC Jr, Mccall BW. Pressure-flow studies in hypertrophic subaortic stenosis. J Clin Invest. 1964;43:401-7.

22. Criley JM, Siegel RJ. Obstruction is unimportant in the pathophysiology of hypertrophic cardiomyopathy. Postgrad Med J. 1986;62:515-29.

23. Siegel RJ, Criley JM. Comparison of ventricular emptying with and without a pressure gradient in patients with hypertrophic cardiomyopathy. Br Heart J. 1985;53:283-91.

24. Ross RS, Criley JM, Lewis KB, White RI Jr, Wilson WS. Isometric contraction in late systole-a new explanation for the intraventricular pressure differences in idiopathic hypertrophic subaortic stenosis (IHSS). Trans Am Clin Climatol Assoc. $1966 ; 77: 48-57$

25. Wilson WS, Criley JM, Ross RS. Dynamics of left ventricular emptying in hypertrophic subaortic stenosis. A cineangiographic and hemodynamic study. Am Heart J. 1967:73:4-16.

26. Occhetta E, Corbucci G, Bortnik M, Pedrigi C, Said SA, Droste HT, et al. Do electrical parameters of the cardiac cycle reflect the corresponding mechanical intervals as the heart rate changes? Europace. 2010;12:830-4.

27. Orme NM, Sorajja P, Dearani JA, Schaff HV, Gersh BJ, Ommen SR. Comparison of surgical septal myectomy to medical therapy alone in patients with hypertrophic cardiomyopathy and syncope. Am J Cardiol. 2013;111:388-92.

Key Words: hemodynamics, hypertrophic cardiomyopathy, aortic stenosis, obstruction, stroke volume 
TABLE E1. Hemodynamic changes after premature ventricular contraction in patients with hypertrophic obstructive cardiomyopathy and aortic stenosis

\begin{tabular}{|c|c|c|c|c|c|c|}
\hline \multirow[b]{2}{*}{ Changes after PVC } & \multicolumn{3}{|c|}{ Prebypass } & \multicolumn{3}{|c|}{ Postbypass } \\
\hline & HOCM & $\mathbf{A S}$ & $P$ value & HOCM & $\mathbf{A S}$ & $P$ value \\
\hline Peak LVP (mm Hg) & $47.7 \pm 18.8$ & $21.7 \pm 20.2$ & .023 & $1.3 \pm 6.9$ & $-1.5 \pm 8.0$ & .478 \\
\hline P-P gradient $(\mathrm{mm} \mathrm{Hg})$ & $57.7 \pm 24.8$ & $20.3 \pm 12.2$ & .003 & $4.7 \pm 6.0$ & $1.5 \pm 1.8$ & .185 \\
\hline MI gradient $(\mathrm{mm} \mathrm{Hg})$ & $70.9 \pm 29.9$ & $25.8 \pm 10.4$ & .003 & $7.5 \pm 2.2$ & $10.6 \pm 3.9$ & .080 \\
\hline Max LV dp/dt $(\mathrm{mm} \mathrm{Hg} / \mathrm{s})$ & $333 \pm 248$ & $528 \pm 274$ & .173 & $314 \pm 150$ & $319 \pm 227$ & .963 \\
\hline Peak LAP (mm Hg) & $3.1 \pm 6.6$ & $1.1 \pm 2.2$ & .453 & $1.0 \pm 2.5$ & $-1.1 \pm 1.1$ & .071 \\
\hline Mean LAP (mm Hg) & $0.9 \pm 2.5$ & $-0.2 \pm 1.2$ & .275 & $-0.1 \pm 1.1$ & $-0.6 \pm 0.9$ & .353 \\
\hline LAP V wave $(\mathrm{mm} \mathrm{Hg})$ & $0.1 \pm 7.3$ & $1.4 \pm 2.1$ & .640 & $-2.2 \pm 2.8$ & $0.5 \pm 1.8$ & .045 \\
\hline $\operatorname{ETc}(\mathrm{ms})$ & $50 \pm 36$ & $-9 \pm 38$ & .009 & $13 \pm 17$ & $9 \pm 25$ & .684 \\
\hline Peak flow $(\mathrm{mL} / \mathrm{s})$ & $10 \pm 26$ & $103 \pm 54$ & .003 & $90 \pm 14$ & $100 \pm 60$ & .676 \\
\hline Max flow df $/ \mathrm{dt}\left(\mathrm{mL} / \mathrm{s}^{2}\right)$ & $1014 \pm 1042$ & $1583 \pm 1577$ & .419 & $1154 \pm 535$ & $2821 \pm 1564$ & .014 \\
\hline Stroke volume $(\mathrm{mL})$ & $-7.5 \pm 8.7$ & $12.9 \pm 7.8$ & $<.001$ & $8.8 \pm 5.1$ & $13.6 \pm 13.8$ & .412 \\
\hline Stroke index $\left(\mathrm{mL} / \mathrm{m}^{2}\right)$ & $-3.9 \pm 4.3$ & $6.9 \pm 4.3$ & $<.001$ & $4.7 \pm 2.8$ & $7.2 \pm 7.1$ & .401 \\
\hline
\end{tabular}

$P V C$, Premature ventricular contraction; $H O C M$, hypertrophic obstructive cardiomyopathy; $A S$, aortic stenosis; $L V P$, left ventricular pressure; $P-P$, peak to peak; $M I$, maximal instantaneous; $L V$, left ventricular; $L A P$, left atrial pressure; $E T c$, corrected ejection time. 